\title{
Sustainable Development Goals Connectivity Dilemma
}

\author{
Abbas Rajabifard \\ Centre for SDIs and Land Administration, The University of Melbourne, Aus- \\ tralia
}

\subsection{Introduction}

In the context of United Nations Global Geospatial Information Management (UN-GGIM) and the development of Sustainable Development Goals (SDGs), recalling Economic and Social Council resolution 2011/24, of 27 July 2011, which established the UN-GGIM to provide a forum for coordination and dialogue among Member States, and to hold regular high-level, multi-stakeholder discussions on global geospatial information, including through the convening of global forums, with a view to promoting a comprehensive dialogue with all relevant actors. Further also recalling the establishment of the UN-GGIM Academic Network in July 2016 as a strategic research and training arm for UN-GGIM to assist members, and recalling Economic and Social Council resolution 2016/27 entitled 'Strengthening institutional arrangements on geospatial information management' of 27 July 2016, in which the Council acknowledged the considerable achievements of the Committee of Experts including: its contribution to the strengthening of geospatial information management capacities and utilization in developing countries; the efforts to streamline the work of the subsidiary bodies of the Council in the field of geospatial information management; and its role in the implementation of the 2030 Global Agenda for Sustainable Development, the Sendai Framework, and other global development agendas within the purview of the United Nations.

Also recalling General Assembly resolution 70/1 entitled 'Transforming our World: The 2030 Agenda for Sustainable Development' of 25 September 2015, which recognizes the need for new data acquisition and integration approaches to improve the availability, quality, timeliness and disaggregation of data, and the use of a wide range of data, including earth observations and geospatial information, to support the implementation of the new development agenda at all levels, while ensuring national ownership in supporting 
and tracking progress; noting the opening statement of the Secretary-General at this Congress, in which he emphasized that our expertise and guidance in geospatial data, methods, frameworks, tools, and platforms is urgently needed, and that reliable, timely, accessible and disaggregated geospatial information must be brought to bear to measure progress, inform decision-making and ensure effective and inclusive national and sub-national programs that will chart the path towards the 'Geospatial Way to a Better World', to assist in the implementation of the SDGs, and transform our world for the better; and also noting further that United Nations World Geospatial Information Congress (UNWGIC) in November 2018, which has provided a convening, participatory and inclusive environment to enhance the communication, understanding, knowledge and application of geospatial and land information management, to discuss the policy relevance and challenges to advance geospatial science and technology, promote the creation and sharing of more reliable geospatial data, and to enhance value-added applications and services to address local, regional and global challenges; all have highlighted the needs for a roadmap facilitating the achievement of SDGs implementation through the lens of Geospatial information.

With this in mind, this book will provide interdisciplinary analysis and multi-sectoral expertise on the interconnection between the SDGs, geospatial information, the legal, policies and institutional components, technical enabling tools and the way forward to address urban and rural resilience.

Urbanization, natural and human-induced disasters, migration, and technological advancements are among some of the most potent forces that are increasing the connectivity and complexity of the challenges highlighted in the SDGs. Achieving the SDGs across different communities and domains will require the use of geospatial information to overcome challenges such as land rights, food production, disaster risk reduction, safe human settlements, and other social, economic, and environmental issues at local, national, and global levels. Geospatial information and technologies are particularly critical to strengthening urban and rural resilience, where economic, agricultural, and various social sectors intersect.

The SDGs dependency on geospatial information and enabling technologies are mainly due to the primary roles that data and tools for relating people to their location, place and environment, and to measure 'where' progress is, or is not, being made, particularly at sub-national and local levels. However, in the pursuit for sustainable development, many countries continue to face a series of impediments that exacerbate their ability and opportunity to participate fully in the implementation of the United Nations 2030 Agenda, to support national development, economic prosperity, and through that, a global and thriving information economy. These include institutional challenges in data production: having the required human capital and skillsets, effective and sustained access to digital technology, the Internet of Things (IoT), to the provision and exploitation of new data needs, information systems, analytics and associated enabling tools and technologies to support the timely and 
reliable implementation of the SDGs. Examining the SDGs from a geospatial lens will ensure that the challenges are addressed for all populations in different locations, leaving no one behind.

In addition, identifying the gaps and opportunities in understanding the connectivity between different elements of sustainability and resilience requires input from different disciplines and sectors.

\subsection{Addressing SDGs and Land Tenure: The Need for a Roadmap}

The achievement of the SDGs for all communities and jurisdictions require a comprehensive roadmap that encompasses all dimensions of data infrastructure, social, economic, environmental and governance ecosystems.

With this in mind, this book provides interdisciplinary analysis and multisectoral expertise on the interconnection between the SDGs, geospatial information, the legal, policies and institutional components, technical enabling tools and the way forward to address urban and rural resilience. In addition, we discuss the security of tenure targets embedded in the SDGs. We stressed the importance of the land administration and surveying profession owning the SDGs selected targets such as Target 1.4 on ensuring that all men and women have equal rights to land and other forms of property by 2030. Very few countries actually know what their baseline on the security of tenure is and even fewer have a program or plan in place for achieving the target by 2030 .

Similarly and in a broader context, Goals 1, 2, and 5 of the SDGs have designated targets linked to land tenure rights signify the obligation of incorporating land administration in the process of building sustainable and smart cities for all. Therefore, surveyors and geospatial practitioners should work to change this globally and help countries to adopt national programs on security of tenure while addressing SDGs Goals, Targets and Indicators.

The UN-GGIM 2017-2021 Strategic Framework recognizes the necessity of integrating geospatial information in process of achieving the SDGs and developing future cities. Strengthening local, national, and global cooperation to foster the integration of legal and organizational frameworks including the SDGs, UN-GGIM 2017-2021 Strategic Framework, Sendai Framework, and Habitat III Urban Agenda will positively impact disaster management, development of adequate policies and regulations, climate action, efficient urban planning, and good institutional governance.

The availability of effective and efficient land administration - and its economic, social, and environmental implications - remains a problem worldwide, especially in developing countries where mature land administration systems and formal land registration systems are not available. Therefore, spatial in- 
clusion, secure land rights, and sustainable land use are all major challenges of rapid urbanization that public and private sectors need to address in the development of future smart cities.

Considering this situation, the UN-GGIM Academic Network recognizes the importance of promoting and sharing data acquisition and integration approaches, legal and policy instruments, institutional management models, technical solution and standards, interoperability of systems and data, and access to quality and timely data. As a result, the Academic Network aims to work in the direction resolution 2016/27 of the Economic and Social Council (ECOSOC) by promoting the sharing of geospatial data, enhancing capacity building, and inter-institutional cooperation for sustainable development, disaster risk reduction, and policymaking.

With the above context in mind, the large-scale migration from rural to urban areas, and between countries, affects sustainable development at local, national, and regional levels. In order to identify gaps and opportunities to strengthen urban and rural resilience to global challenges, the book will draw upon the discussions and presentations and outcomes of three UN-GGIM Academic Network Forums: "Secure Land Rights and Smart Cities - Making it Work for Sustainable Development" as part of the Seventh Session of the United Nations Committee of Experts on UN-GGIM in New York in 2017, "The SDGs Connectivity Dilemma: Urban Settlements, Resilience, and Sustainability" as part of the Eighth Session of the United Nations Committee of Experts on UN-GGIM in New York in 2018, and "A Sustainable and Resilient World: Capacity Building and Geospatial Research for Implementing the $S D G$ ", as part of the first UN World Geospatial Information CongressUNWGIC in China 2018. Therefore, in the context of SDGs and urban and rural resilience, the main objective of the book is to bring together the expertise of leading geospatial experts, scholars, industry actors, and policy-makers and their perspectives from their respective fields to examine the connection between the SDGs, geospatial information, and urban and rural resilience.

\subsection{Book Structure and Overview}

This book is structured in 5 parts, and the themes and objectives of the book are in line with the critical challenges, gaps, and opportunities raised at all UN-GGIM events and UN-GGIM Academic Network forums. Three main themes are the following:

- the role of geospatial information and data infrastructures and services in achieving the SDGs goals;

- the interactions and relations between various elements of the SDGs; and 
- the significance of geospatial information in strengthening community, infrastructure, and institutional resilience.

The three main objectives of the book are the following:

- provide interdisciplinary analysis and multi-sectoral expertise on the interconnection between the SDGs, geospatial information, and urban and rural resilience;

- examine how geospatial information will support and inform inclusive and even urbanization, resilient development, and the SDGs; and

- present roadmaps for a more holistic approach to integrating geospatial information and technologies in the implementation of the SDGs.

The rest of this section provides a brief overview of the parts and chapters of this book (Figure 1.1).

\section{Part 1. Setting the Scene}

Part 1 provides a context and background to the SDGs connectivity dilemma, with a high level description of what SDGs mean and the impacts of spatial enablement. This part comprises of four chapters, beginning with this Chapter 1, which outlines the context and objectives of the book and discussion about the needs of a roadmap towards achieving SDGs, together with an introduction to the following chapters. Chapter 2 by, Greg Scott and Abbas Rajabifard, put forward the SDGs Roadmap. The chapter addresses the 2030 Agenda for Sustainable Development, anchored by 17 Sustainable Development Goals (SDGs), providing a transformative and integrated approach to sustainable development. With emphasis on measuring and monitoring development progress with reliable policy, science, technology and especially data, the 2030 Agenda presents all countries and the global policy community with a set of significant development challenges that are almost entirely geographic in nature. The chapter also discusses policy challenges, including the strategic leadership, understanding and awareness of national geospatial information policy, frameworks and associated implementation roadmaps. As a tangible means to support the implementation of the SDGs, Greg Scott and I present and discusses the key components of a geospatial roadmap for countries to develop and strengthen their institutional arrangements in national geospatial information management, to bridge the geospatial digital divide, and to measure and monitor development progress. Therefore this chapter will focus on a roadmap towards a sustainable and resilient future for all.

With this, Chapter 3, by Daniel Paez, then addresses the marriage of opposites: strategies for public and private sectors working together in land tenure reform projects that support SDGs. Strategies are presented in this chapter can be used during the design and implementation of future land reform projects both in developed and developing countries as part of empowering SDGs. In order to highlight the role of geospatial information and their ability 
to enable the environment further, Chapter 4 by Maryam Rabiee addresses the social, economic, and environmental impacts of spatial enablement when spatially enabling the SDGs. Ready and timely access to spatial information is critical to making informed decisions on economic, environmental and social issues. This chapter aims to present the significance of spatially enabling the SDGs and the opportunities it provides for the seventeen goals. The chapter investigates the social impact of spatial enablement for the SDGs and ends with a discussion on land, the driving force of spatial enablement for the SDGs.

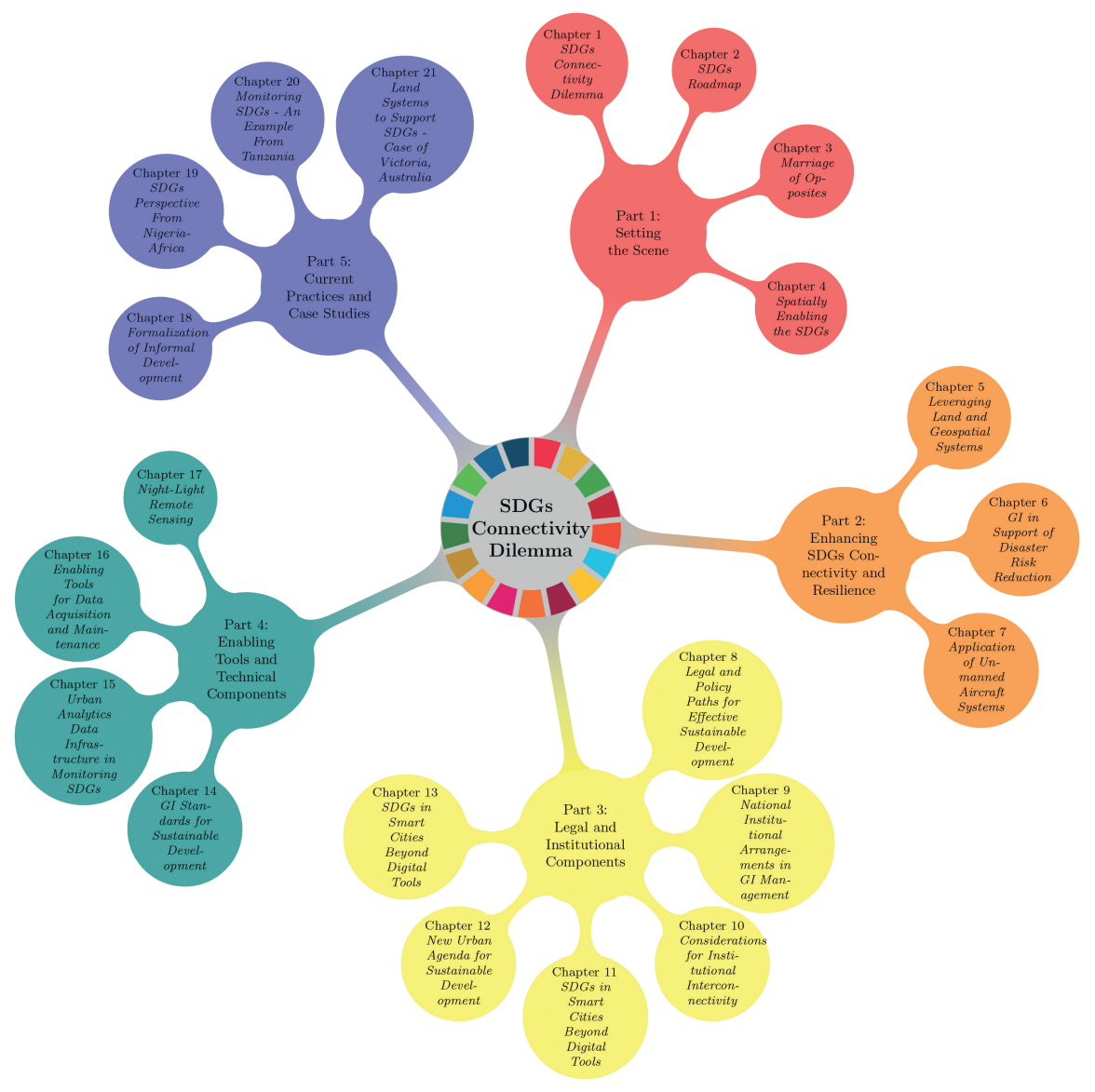

FIGURE 1.1

Overview of the Book

\section{Part 2. Enhancing SDGs Connectivity and Resilience}

In the context of SDGs connectivity, this part examines how geospatial systems can support disaster resilience, risk reduction and improved mapping for better SDG connectivity and better management. As discussed earlier, 
geospatial information can help locate the challenges of communities in different regions more visible and integrating geospatial data with other available data can assist with addressing the 'where' component of different social, economic, and environmental challenges. To highlight the significance of geospatial information in strengthening community, infrastructure, and institutional resilience, this part will present ways, in which geospatial information can assist with narrowing the connectivity gap. This part comprises three chapters, beginning with Chapter 5, where Abbas Rajabifard, Mika Petteri Törhönen, Katie Potts, Federico Barra and Ivelisse Justiniano, address the concept of leveraging National Land and Geospatial Systems for improved disaster resilience. In the context of SDGs this chapter is based on a World Bank flagship project let by the authors of the chapter to present a roadmap for exploring the role of land and geospatial information, the function and responsibility of the institutions that govern the data, and the resulting impact that this data has on the overall resilience of society to disasters. Following this in Chapter 6, Saeid Pirasteh and Masood Varshosaz present geospatial information technologies that can support the UN-GHIM in its efforts in disaster risk reduction, mitigation and resilience, particularly those due to earthquakes. The final chapter in Part 2 (Chapter 7), by Michael J. Starek, Melanie Gingras, and Gary Jeffress explores the application of unmanned aircraft systems as as example of tools for coastal mapping and resiliency. The information and applications presented are applicable to a variety of UN SDGs including sustainable land use for "Life on Land" and sustainable agriculture for crop security and "Zero Hunger".

\section{Part 3. Supporting SDGs: Legal, Policies and Institutional Com- ponents and Capacity Building}

This part discusses the sustainability and resilience challenges that are directly tied to legal, policy, and institutional capacities to make inclusive and effective decisions that positively impact our communities. The Part 3 comprises of five chapters to address legal and institutional gaps and requirements for sustainability and its impact on inclusivity. To begin, Harlan Onsrud puts forward the legal and policy paths for effective sustainable development in Chapter 8. He discusses the requirements and fundamental relationships between legal and policy framework to support SDGs. Next, in Chapter 9, Joep Crompvoets and Serene Ho discuss the issues that have arisen from the UN-GGIM during the sessions over the past 6 years, highlighting the need for developing a framework for national institutional arrangements in geospatial information management. This chapter will provides the rationals and the approach for the development of institutional arrangements in support of geospatial information management as an essential enabler for SDGs. Following this, Chapter 10 by Serene Ho discusses the considerations for institutional interconnectivity. The institutional challenges around the coordination and collaboration in the public sector are reviewed, and a discussion on potential strategies for progression in this space is presented. In Chapter 11, Zhixuan 
Yang and Abbas Rajabifard discuss implementing SDGs for Smart Cities as an example to establish the theoretical framework by exploring key components to observe the implementable structure and action of SDGs at the city level. Particularly, the chapter aims to highlight the fundamental foundations beyond digital tools to achieve SDGs. In chapter 12 Soheil Sabri and Abbas Rajabifard explore the UN-Habitat's initiatives in adoption and localising the SDGs through defining the New Urban Agenda (NUA) 2030. They provide a historical account on how the global urbanisation started to be considered as a threat and ended up to be a potential development tool for the future generation established by the NUA. They also explain the Action Framework for Implementation of NUA (AFINUA) developed by the UN-Habitat to localise the implementation, measurement, and monitoring the SDGs and other associated indicators formulated through City Performance Initiative (CPI). This chapter also draws links between spatial enablement concepts and principles and the key elements of AFINUA. And finally, Chapter 13, by Josef Stobl discusses the development of "Brainware" for SDI. This chapter highlights the importance of academic education in geospatial technologies for building and maintaining the brainware components that will make the SDG framework successful across human societies.

\section{Part 4. Enabling Tools and Technical Components}

Part 4 addresses technology and tools that can assist with monitoring and measuring progress at different levels of governance and across different regions. There are three chapters in this part, beginning with Chapter 14, contributed by a joint standards team from ISO and OGC, Denise McKenzie et al. addressing the role of geospatial information standards for sustainable development. This is followed by Chapter 15, where Abbas Rajabifard and co-authors describe a new research initiative that sees the development of an SDI to support urban analytics and urban research capabilities focused on Australian cities, called Urban Analytics Data Infrastructure (UADI). The UADI provides opportunity for multi-disciplinary, cross-jurisdiction, nationallevel analytics, which appeals the requirements of SDGs and potentially can be scaled up to be used by other nations. The chapter explains about the design of UADI architecture, which seeks to provide the urban research community with a digital infrastructure that responds to current challenges related to data access, sharing and driving the SDG indicators. Chapter 16 by Gottfried Konecy discusses technical enabling tools for data acquisition and maintenance of topographic data of urban and high mountain areas. This chapter explores data resolution, global progress in mapping, new mapping alternatives and how these relate to achieving SDGs. The last chapter in this part by Huayi $\mathrm{Wu}, \mathrm{Xi} \mathrm{Li}$, Deren Li, addresses night-light remote sensing, a tool which can be used towards achieving SDGs. Case studies are presented showing how night-light remote sensing can plat a very important role in the assessment of humanitarian disasters. 


\section{Part 5. SDGs Perspectives}

This part of the book looks at what the current state of play is for SDGs around the world, and specific case studies and cases are discussed in four chapters. It begins with Chapter 18, where Chryssy Potsiou brings together a wealth of knowledge as a leader of the field, compiling over 20 years of research, in cooperation with the FIG, the World Bank, UNECE and government agencies around the world to address why and how informal development should be formalized quickly, inclusively and affordably. Chapter 19 by Muyiwa Agunbiade, Olajide Oluwafemi, and Oluyemi Akindeju gives a perspective from Nigeria, Africa. This chapter discusses SDGs connectivity by exploring the nature of interlinkages between the SDGs from the lens of geospatial information and geospatial data infrastructure. It also focuses on evolving an integrated framework towards achieving SDGs in developing economies. Chapter 20 by Maria Antonia Brovelli, Maria Ilie Codrina and Serena Coetzee, discusses Openness and Community Geospatial Science for monitoring SDGs, giving an example from Tanzania for SDGs Goal 9. The authors, focus on these two aspects: openness and community geospatial science, presenting concepts and examples of open data and open software with reference to citizen science and volunteered geographic information. The final chapter in this part, by Hamed Olfat and Davood Shojaei examines the Case Study of Victoria, Australia for modernizing land administration systems to support the SDGs.

Sustainable development and resilience are continuous paths towards a better future for all. We must ensure that our contribution to this domain of knowledge has long-term impacts towards leaving no one behind. 